\title{
Brain science benefits from budget plan
}

Tokyo. The potential benefits of a new five-year plan for science and technology put forward last month by Japan's Council for Science and Technology are already becoming apparent. The Science and Technology Agency (STA) has drafted an ambitious plan to invest $¥ 2,000$ billion (US\$18 billion) in brain science over the next 20 years, and more than $¥ 100$ billion in a state-of-the-art nuclear magnetic resonance (NMR) centre for studying the structure of protein molecules.

Both proposals need to be approved by STA's finance section before a request is submitted in late August to the Ministry of Finance, where they will undergo close scrutiny before the national budget is announced in December. But optimists argue that the government's commitment to science funding, which was enshrined in a science and technology law passed last year, will ensure that the plans will be approved with only minor trimming (see Nature 378, 227; 1995).

The five-year plan calls for an increase of more than 50 per cent in the government's spending on science and technology, much of it to strengthen basic research in universities and government research laboratories, and was approved by the cabinet (including the Ministry of Finance) late last month.

Some people claim that the plan's emphasis on expanding basic research contrasts with moves in other advanced economies to make research more commercially relevant. But others, such as Keisuke

\section{Finland urges increase in EU research funds}

Munich. Finland has become the first member of the European Union (EU) formally to advocate an increase in funds for the European Commission's Fifth Framework Programme for research (FP5), due to be launched in 1998.

In a position paper on FP5, Finland also calls for a greater concentration of funds within fewer programmes, and increasing emphasis on training and mobility programmes for young scientists, as well as on the exploitation of the results of research projects.

All are in line with an emerging consensus among member states about how FP5 might be run more efficiently than the current framework programme.

Finland also suggests that FP5 should be open to non-member industrialized countries to allow the creation of global research consortia. It wants cooperation to be strengthened with the central and eastern European countries that have applied for membership of the EU.

Alison Abbott
Toyama of Kyoto Prefectural Medical University, a member of the STA committee that drafted plans for the brain research programme, say it will simply bring Japan's balance between basic and applied research into line with other advanced countries.

The proposed brain science research programme will be organized around a new brain research institute, which will form the hub of a network of designated laboratories chosen from university and government centres that are already engaged in brain-

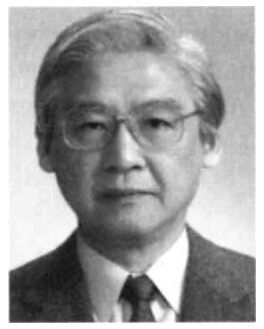

Ito: masterminded brain science plan. related research. Overseeing the project will be a coordinating committee, which will foster cooperation between the ministries and agencies operating the laboratories.

The committee that drafted the brain science plans is chaired by Masao Ito, president of the Science Council of Japan (JSC) and director general of the Frontier Research Programme of the Institute of Physical and Chemical Research (RIKEN). Ito, who is one of Japan's leading brain researchers, says he is extremely pleased with the plan; "this has been our dream".

Ito says the ambitious budget proposed for this project is a direct result of the government's five-year plan, and that brain research is an area ripe for development. 'It is time to push it forward,' he says. Japan at present spends less than one-tenth of the budget of the US National Institutes of Health (NIH) on brain research, and has only about 3,000 researchers, compared to 25,000 in the United States. The proposed budget, which would amount to $¥ 100$ billion (US\$1 billion) a year, would bring Japan's spending close to that of the NIH.

Ito admits that researchers in other areas of science may regard the planned budget with jealousy. But he insists that life science has in the past been "poorly supported", and is therefore in need of special extra support. "Disciplines such as physics and chemistry have been well supported, but interdisciplinary areas such as brain research have been neglected," he says.

The new brain research institute is likely to be based at RIKEN, as more than half of about 25 frontier research projects there are concerned with brain research. Other laboratories likely to attract funding include the Ministry of International Trade and Industry's Electrotechnical Laboratory and Institute for Bioscience and Human Technology in Tsukuba, north-east of Tokyo, and the Education Ministry's Brain Research Institute at Niigata University, west of the capital. Roughly half the money will go to the central institute and half to the other laboratories.

The plan, which addresses issues raised by a JSC document on brain research released in May (see Nature 381, 266; 1996), sets out three major areas of research: basic research into the structure and function of the brain; medical research aimed at the prevention and treatment of neurological disorders; and research aimed at mimicking the brain's information-processing functions. Forty-seven projects that fit into these categories have already been planned.

Other indications that the five-year plan is producing benefits for science include an STA proposal for an NMR centre for studying protein structures. Initial plans for the centre suggested it would have a budget of $¥ 50$ billion (see Nature 381, 105; 1996). But a figure more than twice as large is now being discussed, thanks to the "favourable climate" introduced by the five-year plan, says an STA official in charge of the programme. The agency was due to release detailed research goals for the new structural biology research project on 11 July (see below).

Stephen Barker

Research aims of Japan's new NMR centre for structural biology:

- Elucidation of all basic protein

structures.

- Analysis of multi-molecular protein complexes.

- Prediction of the 3D structure of proteins from the amino-acid sequence. - Determination of the relationships between the higher order structure of proteins and their functions.

- Understand the biological significance of protein structures.

- Manipulate the function of proteins by changing their molecular structure.

Technology to be developed:

- Large-scale X-ray crystallography systems for determining the structure of proteins with molecular weights in excess of 1 million daltons.

- Superconducting magnets with a power of $1 \mathrm{GHz}$ for NMR analysis of large proteins.

- Electron microscope technology for the analysis of membrane bound proteins and other large molecules.

- Neutron scattering crystallography technology.

- Techniques to examine the molecular structure within cells using atomic force and light microscopes.

- Theoretical and computational modelling technology to understand mechanisms of molecular interactions and to determine 3D protein structures purely from genome information. 